\title{
TRATAR E EDUCAR: ESCRITA E ALFABETIZAÇÃO DE CRIANÇAS COM TRANSTORNO DO ESPECTRO Autista (TEA)
}

\section{Marise Bartolozzi Bastos}

Um dos principais problemas enfrentados na escolarização de crianças com Transtorno do Espectro Autista (TEA)' é o fato de que esses alunos experimentam muita dificuldade para estabelecer uma relação socializada com os outros, o que dificulta e restringe suas possibilidades de aprendizagem e circulação social.

No entanto, sabe-se que a escola pode oferecer a essas crianças mais do que a chance de aprender, pois, sendo um discurso social importante, ela oferece uma certidão de pertinência ao oferecer-lhes o lugar de "aluno".

Com a inclusão, aposta-se no poder das diferentes produções discursivas postas em circulação no interior do campo escolar, a fim de delinear, assegurar e sustentar um lugar para essas crianças - aluno/criança -, uma vez que uma designação de lugar social é especialmente importante para as crianças que enfrentam dificuldades estruturais no estabelecimento do laço social, como o caso de crianças com TEA.

Nesse sentido, a inclusão funcionaria como uma aposta de que essa circulação discursiva - ocupar o lugar de aluno na escola - produza efeitos de subjetivação para essas crianças, já que a instituição escolar oferece as leis que regem as relações entre os humanos para que delas a criança se aproprie daquilo que lhe for possível.

Contudo, sabemos que é extremamente penoso para os educadores terem em sala de aula alunos imunes ao estabelecimento do laço e do contato social, que não têm curiosidade pelo conhecimento e não entram no regime das relações e trocas sociais, pois participam de maneira atípica de atividades grupais.

Kupfer e Petri (2000) fazem um alerta a esse respeito: "esse alto custo inclui, por exemplo, um enorme estrago na saúde mental de muitos professores, que não podem e não sabem abordar a inclusão, e terminam por apelar para o afastamento, a licença médica" (p. I |0).

\footnotetext{
I Transtorno do Espectro Autista (TEA) é o termo utilizado na última edição do Manual diagnóstico e estatístico de transtornos mentais (DSM-V) lançado em 2013. Anteriormente, no DSM-IV, havia cinco transtornos descritos separadamente e cada um deles tinha um diagnóstico único: Transtorno Autista ou Autismo Clássico, Síndrome de Asperger, Transtorno Invasivo do Desenvolvimento, Síndrome de Rett e Transtorno Desintegrativo da Infância. Na última revisão do DSM, esses transtornos deixaram de figurar como diagnósticos distintos e passaram a compor o TEA (Transtorno do Espectro Autista), com exceção da Síndrome de Rett, que passou a ser destacada do Espectro Autista. Na Classifcação Internacional de Doenças (CID- I0), da Organizacão Mundial de Saúde, a nomenclatura adotada é Transtornos Globais do Desenvolvimento (TGD) e corresponde ao CID 10 - F84. Os psicanalistas seguem usando os termos autismo e psicose, apesar deste último ter sido banido do DSM. O termo ainda figura no CID 10 como Transtornos psicóticos.
} 
A inclusão escolar enquanto direito e garantia da cidadania é fato indiscutível, mas deve-se questionar e discutir sobre as crenças pedagógicas vigentes para ampliar esse processo de fato.

trabalho de escolarização das crianças com TEA exigirá dos professores uma reflexão sobre os processos usuais de ensino e aprendizagem, bem como um olhar diferente que leve em conta um aluno que não está em posição de curiosidade como os outros, mas que aprende de maneira idiossincrática e pouco convencional. Sabemos que isso apresenta-se como um enigma e um grande desafio para os educadores: afinal, como ensinar a quem não tem curiosidade, a quem não demanda saber do professor?

Nesse sentido, as tentativas de manter essas crianças na escola nunca foram uma tarefa de fácil execução. As perguntas mais frequentes trazidas pelos professores costumam ser: "como trabalhar com essas crianças, se não somos especializados no tipo de dificuldade que elas têm?", "como alfabetizar um aluno que não tem curiosidade pela leitura e pela escrita e só tem interesse por cálculos matemáticos?" ou "como ensinar o conteúdo escolar a um aluno que não dirige a palavra nem o olhar ao professor?".

As inquietações dos professores têm, como pano de fundo, o discurso pedagógico tradicional que atrela os processos educacionais às noções de desenvolvimento oriundas do campo da psicologia e preconiza como tarefa da educação escolar implementar os processos de desenvolvimento, sobretudo o cognitivo.

A ênfase que o campo escolar dá aos aspectos do desenvolvimento (muitas vezes tomados como exclusivamente determinados no âmbito biológico) inviabiliza que um professor tome como aluno uma criança com TEA e vislumbre a possibilidade de alfabetizá-la, pois a vê como uma criança com importantes atrasos no desenvolvimento por estar diante de um aluno que não fala, não responde às solicitações que the são dirigidas, não brinca com as outras crianças, apresenta grafismo rudimentar e, portanto, parece uma criança muito aquém dos processos de alfabetização e letramento.

Diante desse aluno, o professor sente-se muito pouco habilitado para exercer sua tarefa educativa e, muitas vezes, supõe que esse aluno só poderá dar conta de atividades propostas para o segmento da educação infantil.

Nesse ponto, é preciso indagar se as proposições da pedagogia hegemônica podem ser postas em questão de modo a permitir que a escola repense suas práticas fora de uma perspectiva desenvolvimentista, para poder, então, tomar essa criança como aluno, não exclusivamente pela ótica do desenvolvimento de suas capacidades cognitivas, mas incluindo a dimensão do sujeito psíquico ${ }^{2}$ que a psicanálise aponta não coincidir com o desenvolvimento biológico, pois só assim poderá abrir espaço para que novas formas de aprender e ensinar sejam viabilizadas no contexto escolar.

desafio para a instituição escolar é que a inclusão dessas crianças requer um processo com transformações importantes, sobretudo na maneira como os educadores concebem a relação com o saber e o conhecimento em uma perspectiva desenvolvimentista, posto que parametrados pelo discurso pedagógico hegemônico.

2 Para a psicanálise, o sujeito psíquico é o sujeito sujeitado ao desejo que Freud descobriu no inconsciente e se manifesta de forma privilegiada nos lapsos, sonhos, atos falhos, sintomas, entre outros. Para Lacan, é o sujeito dividido pelo plano da linguagem. 


\section{ESCRITO INCONSCIENTE E ESCRITA ALFABÉTICA: TRATAR/EDUCANDO E EDUCAR/TRATANDO}

O sistema nervoso constitui a superfície material receptiva aos registros das experiências internas e externas que aos poucos se organizam para constituir um mundo interno e uma realidade externa, mas o psiquismo não pode ser reduzido ao aparato neurológico.

A abordagem psicanalítica sugere uma compreensão do humano como habitante da ordem da linguagem. Freud destacou o papel das palavras e dos traços mnêmicos na construção do aparelho psíquico, e as formulações de Lacan ( 1998) permitiram uma maior compreensão da constituição psíquica por meio de sua hipótese do inconsciente estruturado como uma linguagem, ou, dito de outro modo, como o discurso do Outro ${ }^{3}$.

Em seus primeiros estudos, Freud já demonstrava interesse em compreender o processo pelo qual as experiências humanas eram inscritas no aparelho psíquico e de que modo essas percepções eram registradas e transformadas para dar origem às imagens e ideias elaboradas pelo psiquismo. Em seu texto Projeto de uma psicologia científica ( I 895/1976a), sua grande questão era investigar os processos de funcionamento da memória e o modo como as percepções humanas se registram e podem ser recuperadas pela consciência.

Em 1896, na carta 52, Freud escreve a Fliess contando que está trabalhando "com a hipótese de que nosso mecanismo psíquico formou-se por um processo de estratificação: o material presente em forma de traços de memória estaria sujeito, de tempos em tempos, a um rearranjo segundo novas circunstâncias - uma retranscrição" (1950[1896]/1976b, p.317).

Para explicar a constituição do aparato psíquico, Freud constrói a hipótese de que o recalque originário ${ }^{4}$ (Urverdrängung) operaria como primeiro processo de clivagem inscrevendo um conjunto de traços mnésicos que fundaria o inconsciente e tornaria possível todos os recalques posteriores (Nachdrängen). Nesse momento mítico da estruturação psíquica, o inconsciente surge como um escrito, um conjunto das inscrições das representações pulsionais banidas do sistema consciente (Freud, I 895/1976a).

Sendo a exclusão da representação e sua inscrição inconsciente um mesmo ato, a inscrição de que se trata é a de um traço, que, por si só, não remete a sentido nenhum. Cada um desses traços não significa nada em si mesmo, mas, pela associação, por semeIhança ou simultaneidade, permitirão efeitos de sentido. Poderíamos pensar que se trata de algo semelhante às letras que, por si mesmas, nada significam, mas aos serem combinadas, mediante os ordenamentos da língua, escrevem um texto.

3 Outro é o conceito que remete ao lugar da linguagem, ao código, ao tesouro dos significantes. Define a língua, a estrutura da linguagem, as leis, a cultura. Diferencia-se do outro como o semelhante. O outro (semelhante) pode encarnar o Outro (o lugar do código). O Outro (grafado com maiúscula) é a proposição lacaniana que marca o lugar simbólico da falta, do desejo, que impulsiona o sujeito, na condição de objeto, a suturá-lo. Segundo Chemama (1995), "é o lugar onde a psicanálise situa, além do parceiro imaginário, aquilo que, anterior e exterior ao sujeito, não obstante o determina".

4 O recalque originário é um processo estruturante que dá lugar ao surgimento de uma subjetividade onde existia apenas uma objetividade. Dito de outro modo, é graças à mediação que a linguagem opera no homem, deixando-o irreversivelmente separado do mundo natural, que o sujeito do inconsciente se constitui em um sujeito desejante. 
Freud (1950[1 896]/1976b) usa termos como inscrição, transcrição e retranscrição para falar de sua hipótese de que o aparelho psíquico tenha se formado por um processo de estratificação sucessiva que de tempos em tempos possibilita que esses traços mnêmicos inscritos possam se reordenar segundo novos nexos como um processo de retranscrição.

Segundo as leis do processo primário que regem o funcionamento do inconsciente (condensação e deslocamento), essas marcas, inicialmente inapreensíveis pelo sentido, transformam-se, associando-se e combinando-se em efeitos de sentido, e produzem significação.

Portanto, desde sua chegada ao mundo, o filhote de humano se vê lançado a fazer escolhas, ou seja, o reconhecimento dos significantes (Bejahung freudiana, juízo de atribuição) que caminha ao lado do recalcamento.

É assim que Freud formula a constituição dos dois sistemas psíquicos, consciente e inconsciente, que, a partir dos ensinamentos de Lacan, chamamos a ordem simbólica do discurso e lalangue (as associações inconscientes recalcadas).

Essa barreira do recalcamento que incide na linguagem opera ao mesmo tempo com os objetos corporais (extração do objeto a). Na constituição subjetiva, paralelamente ao processo de recalcamento que funda o inconsciente dando lugar às duas ordens do discurso, faz-se também o trabalho de apagamento do corpo, uma vez que o corpo biológico não é puro real da carne, ao se abrir para o mundo por meio de seus orifícios (boca, ânus e olhos), lugares de mediação com o Outro e de satisfação pulsional.

Seguindo as formulações lacanianas, as duas operações de causação do sujeito seriam a inscrição do sujeito na linguagem no processo de alienação (a operação de recalcamento que funda o inconsciente freudiano) e o barramento por meio do objeto, nesse processo de separação (o id freudiano, reservatório das pulsões). Dito de outro modo, o sujeito é dividido pelo recalcamento, que se refere à linguagem, e pelo objeto, causa do seu desejo, cuja verdadeira natureza ele ignora. Portanto, não pode ser senhor absoluto nem de sua fala, nem de suas pulsões.

Sabemos, portanto, que o inconsciente freudiano já nasceu em articulação com a noção de escrita, e Lacan irá retomar as proposições freudianas com sua formulação de que o inconsciente está estruturado como linguagem.

Lacan (2003), em O seminário, livro 9: a identificação, 1961 - 1962, aborda o tema da constituição do sujeito e do significante e dirá que a constituição de todo e qualquer significante ocorre necessariamente em três tempos: inicialmente há a inscrição de um traço - primeira marca recebida pelo sujeito (SI), seguida por seu apagamento ou rasura, que corresponderia ao que Freud propõe como a operação de recalcamento, permanecendo inconsciente, e, por fim, um terceiro momento em que o sujeito pode se dizer a partir da interpretação que faz das marcas que lhe foram inscritas.

Assim, a criança que nasce tecida no campo do Outro materno poderá desfazer os alinhavos dessa costura que a inscreveu no campo dos humanos para recortar-se na sua singularidade de sujeito desejante, posto que faltante.

Habitualmente, pensa-se a produção escrita das crianças apenas como uma representação da fala. 
Kupfer (2007) afirma:

Se a escrita fosse apenas uma representação da fala, não faria diferença falar de palavra escrita ou falada. Acontece que, ao se imprimirem, as marcas do Outro o fazem segundo uma legalidade precisa. Essa legalidade é a da lógica da escrita, a de sua estrutura. Uma legalidade muda, sem voz alguma. A fala é apenas seu veículo. que se marca não são as marcas sonoras ou visuais, mas um sistema, regido por leis que são leis organizadoras de marcas, de traços, de registros (p.55).

A formulação lacaniana de que o inconsciente está estruturado como linguagem baseia-se na concepção freudiana de inconsciente estruturado como escrito.

A partir do escrito inconsciente, se organizam as demais escritas: o sonho, o desenho e a escrita alfabética. A aquisição da escrita supõe o caminho de uma criança na passagem do escrito à escrita alfabética.

Kupfer (2007) assinala que essa noção da estrutura do inconsciente como um escrito é de fato revolucionária.

Há nela uma predominância do escrito sobre o falado, e essa ideia já se encontrava na Interpretação dos Sonhos (Freud, 1900). Desse modo, até mesmo a ideia clássica da alfabetização, segundo a qual a escrita é a representação da fala fica subvertida (p.5).

É agora a fala que passa a ser uma espécie de representação do escrito inconsciente. Não é isso que Freud (1900) escreve quando se refere à regressão às imagens que o sonho realiza? Para ele, as primeiras inscrições são anteriores à palavra, e são elas que retornam no sonho: "A escrita alfabética não é um modo de representação da fala e pode ser pensada, assim como a própria fala, como desdobramento da relação do sujeito com a ordem da linguagem" (p.56).

A partir das formulações de Freud e Lacan, os psicanalistas colocam em questão a ideia de que a fala veio primeiro, e a escrita surgiu para representá-la. É a fala que passa a ser uma espécie de representação do escrito inconsciente.

Gérard Pommier ( 1996), em seu livro Nacimiento y renacimiento de la escritura, assinala que a aprendizagem da escrita está para além do domínio de uma técnica de alfabetização ensinada na escola.

Segundo o autor, o surgimento da escrita requer a operação psíquica do recalcamento, portanto, se uma criança ainda não pode escrever, não é por falta de maturidade, prontidão ou por problemas em seu desenvolvimento cognitivo, mas porque há um caminho subjetivo a ser percorrido antes da construção da escrita: "Antes de estar em condições de formar palavras [a criança] já levou a cabo operações muito mais complexas do que fazer corresponder um som a um signo" (Pommier, 1996, p. I I, tradução nossa). 
Se o surgimento da escrita requer a operação do recalque, como pensar o trabalho de escrita propiciando efeitos organizadores ou estruturantes para crianças psicóticas e autistas, se o que lhes escapa é exatamente a operação do recalcamento?

Nesse ponto, vale lembrar a observação feita por Lacan (1985) sobre a psicose na infância: "a psicose não é estrutural, de jeito nenhum, da mesma maneira, na criança e no adulto [... s sobre este ponto ainda não temos doutrina nenhuma" (p. I35).

Bernardino (2005) discute a maleabilidade das estruturas psíquicas na infância e assinala a contribuição de Alfredo Jerusalinsky para o tema:

[...] a infância reconhece a possibilidade de estados provisórios, não decididos, que vão se decidir tardiamente quanto à estrutura. $\mathrm{E}$ tem o que chamo de psicoses não-decididas, ou indecididas, porque realmente não se produziu uma inscrição definitiva, há uma espécie de suspense, de escansão, de dilatação desse momento de inscrição, de captura da criança no campo da linguagem numa posição subjetiva (Jerusalinsky, 1993b, p.23 citado por Bernardino, 2005, p.35).

Nesse sentido, na psicose infantil e no autismo, a relação do sujeito com a linguagem pode ser reordenada pela via da escrita, uma vez que o escrito inconsciente é o suporte para a escrita alfabética. Se existe um paralelismo entre essas duas escritas, poderíamos dizer que a escrita alfabética pode servir ao psicótico como uma via de suplência, uma nova possibilidade de estruturação psíquica produzida a partir da inscrição de traços que teriam um caráter subjetivante, ou seja, de construção ou reconstrução do sujeito (Kupfer, 20 I0).

A escrita tem força de subjetivação porque não exprime categorias fixas. Suas propriedades fazem dela jogo de relações, por conta da polissemia da língua, do deslizamento e da mudança de estatuto das unidades conforme o movimento que se estabelece entre unidades.

Trata-se de um processo de mão dupla, em que o corpo precisa estar formado, bordejado, para poder escrever, ao mesmo tempo em que ganha bordas por meio do ato de escrever. Ao escrever, um sujeito se escreve também. A apresentação de um Outro regulado pela lei, neste caso o Outro da escrita, pode pacificar o sujeito (Baio, 2003). Pode, em outras palavras, introduzir, em certa medida, o recalque (Kupfer, 2007, p.6I).

No movimento gradual de aquisição da escrita, uma criança poderá colocar em marcha uma operação de linguagem de dupla mão: uma escrita será construída, mas também um sujeito se construirá como efeito da construção da escrita. Ao mesmo tempo que se constrói uma escrita, ela o constrói, em um jogo de reorganização do campo simbólico ou da linguagem. 
A proposta de trabalho com a aquisição da escrita no tratamento de crianças psicóticas e autistas é uma marca da prática da Educação Terapêutica ${ }^{5}$.

Não são muitos os lugares em que se alfabetiza uma criança psicótica como forma de tratar dela. Nessa forma de tratar educando, o sujeito estará sendo convidado a sujeitar-se, e não libertar-se, pois deverá entrar no pacto da língua escrita. (Kupfer, 2010, p.273).

Podemos dizer, então, que nessa forma de tratar educando, educa-se tratando, uma vez que o sujeito será convidado a sujeitar-se ao funcionamento da estrutura da língua e curvar-se ao ordenamento do código da linguagem, mas é feita uma aposta de que a escrita alfabética possa oferecer ao sujeito uma "nova chance de ordenar sua relação com o Outro ou com a linguagem, instituindo uma Lei, a legalidade da escrita, no lugar da Lei do Pai, a partir da qual o sujeito psicótico teá a possibilidade de emergir vez por outra e dizer-se" (Kupfer, 2010, p.273).

\section{SOBRE A ALFABETIZAÇÃO DE CRIANÇAS COM TEA: A ESCOLA COMO FERRAMENTA TERAPÊUTICA}

trabalho de alfabetização dessas crianças no âmbito escolar é uma forma de ajudá-las a construir outros modos, talvez mais flexíveis, de referência à linguagem, abrindo possibilidades de laço social pela via da escrita. Os livros escritos por autistas de alto funcionamento atestam o uso da escrita para transmitir uma história de exílio em relação à comunicação e ao mundo.

Para as crianças com TEA, estar na escola cumpre uma dupla função, ambas com valor terapêutico: no âmbito educacional, promove a circulação e o laço social e, no âmbito da escolarização propriamente dita, o aprendizado da leitura e escrita promovem para essa criança um reordenamento de sua posição diante do simbólico.

Trata-se, portanto, "de acionar o instrumento da organização cognitiva como forma de prover para a criança um reordenamento de sua posição diante do simbólico ou no interior do simbólico" (Kupfer, 2000, p. 105).

No eixo do trabalho escolar, o professor poderá fornecer para a criança instrumentos como a leitura e a escrita, dentro de suas possibilidades subjetivas e cognitivas,

\footnotetext{
5 Educação Terapêutica é um termo cunhado para "fazer face a um tipo de intervenção junto a crianças com problemas de desenvolvimento - psicóticas, crianças com traços autistas, pós-autistas e crianças com problemas orgânicos associados a falhas na constituição subjetiva -, é um conjunto de práticas interdisciplinares de tratamento, com especial ênfase nas práticas educacionais, que visa à retomada do desenvolvimento global da criança ou à retomada da estruturação psíquica interrompida pela eclosão da psicose infantil ou, ainda, à sustentação do mínimo sujeito que uma criança possa ter construído" (Kupfer (2000, p.83).

A Educação Terapêutica subverte a premissa de que o tratar e o educar sejam atos disjuntos, pois, ao se estabelecerem em uma relação de continuidade, tal como na banda de Moebius, permitem uma nova direção para o tratamento e escolarização de crianças psicóticas e autistas, na qual será possível tratar educando e educar tratando (ver Bastos, 2012).
} 
fazendo uma aposta de que esses instrumentos poderão ser úteis para reordenar o campo simbólico e lidar com a angústia siderativa. Nesse sentido, o educador não terá que ser um especialista em transtornos ou em tratamentos, mas tratará de seu aluno, enquanto educador, uma vez que o tratar é entendido como ato de cuidar dessa criança para que encontre seu estilo próprio de dizer sobre si.

Para ilustrar essa questão e reiterar a importância da escola como dispositivo que opera para essas crianças com a possibilidade de educar/tratar, apresentaremos o percurso de Roberto.

Aos 10 anos, chegou ao Grupo da Escrita 6 . Na época, cursava o $4^{\circ}$ ano, mas os professores sentiam muita dificuldade para abordá-lo pedagogicamente. Era um menino muito quieto, silencioso e um tanto arredio. Não dava trabalho na sala de aula, pois ficava silencioso, observava os colegas e fazia alguns rabiscos no papel.

No Grupo da Escrita, ficava sentado o tempo todo (o grupo trabalhava em torno de uma grande mesa oval), observando a movimentação dos outros participantes do grupo, mas não interagia e não solicitava nenhum material. Sobre a mesa sempre estavam disponíveis materiais gráficos (papel, lápis coloridos, canetas e borracha), livros, revistas, gibis e alguns jogos.

Nos primeiros encontros, apesar dos vários convites feitos pelos coordenadores do grupo, Roberto se restringia a observar a movimentação.

Suas primeiras produções foram:
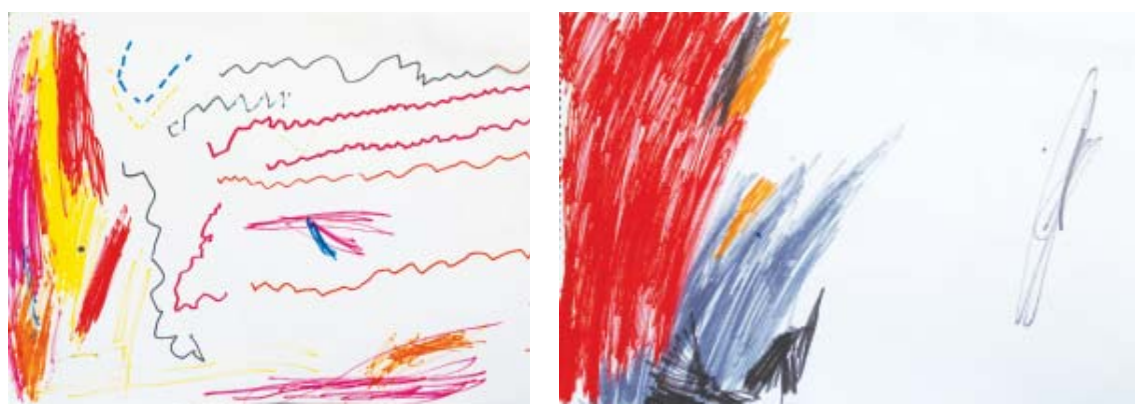

Seguiu fazendo rabiscos coloridos por algum tempo e depois interessou-se por uma régua com figuras geométricas e por letras móveis que usava para fazer o contorno das figuras.

Em algumas oportunidades, os coordenadores aproveitavam para inserir algo que tinha a ver com o trabalho que o grupo estava fazendo (como inserir na folha de Roberto a palavra "VACA" que estava no jogo do Mico partilhado pelos outros integrantes do grupo).

6 Grupo da Escrita refere-se a um dos dispositivos do tratamento institucional oferecido no Lugar de Vida Centro de Educação Terapêutica e refere-se a um dos três eixos da Educação Terapêutica, o escolar propriamente dito (ver Kupfer, 2000). 

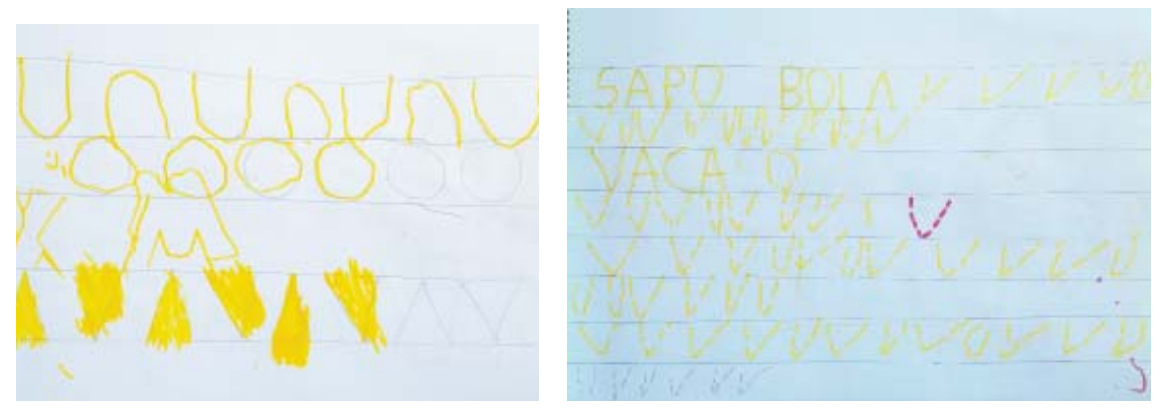

interesse de Roberto por contornos e linhas pontilhadas fez os coordenadores apostarem em uma atividade a partir das conversas das crianças sobre os personagens da Turma da Mônica.

Foi proposto a Roberto que recobrisse com a caneta hidrográfica o nome dos personagens pontilhados à lápis pelos coordenadores.
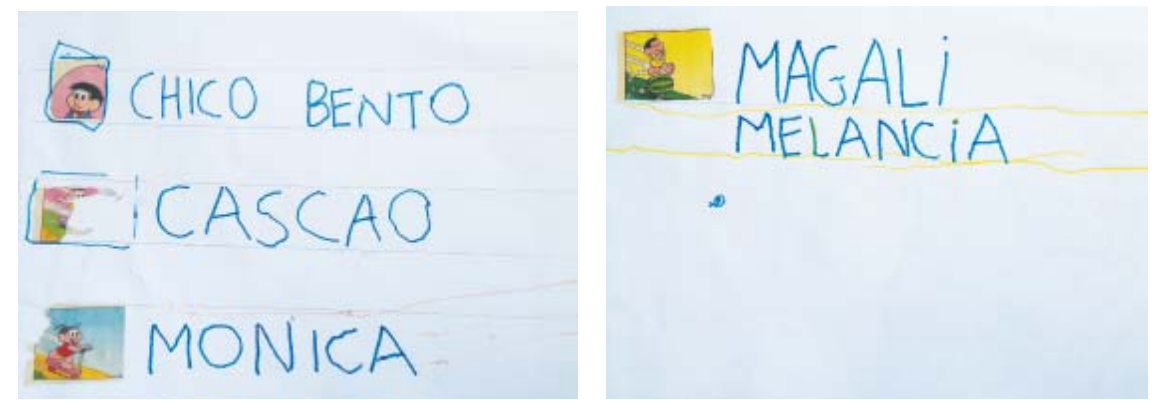

Roberto não só cobriu os pontilhados, como também contornou (fazendo a moldura) cada uma das figuras dadas a ele por um colega do grupo que concordou em ajudá-lo.

O interesse por recobrir palavras escritas com letras pontilhadas aumentou, e Roberto passou a cantarolar canções que, quando reconhecíamos, levávamos para o papel.

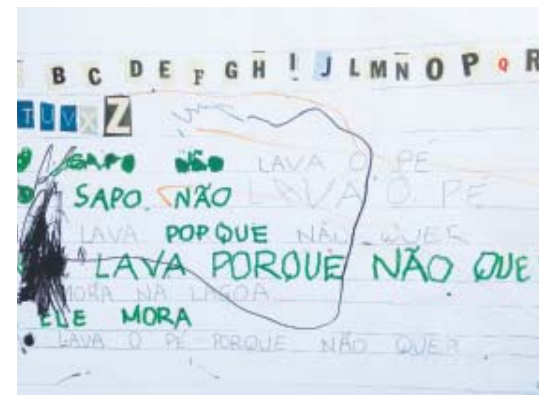

Passados alguns meses do início do trabalho, fomos surpreendidos por uma produção de Roberto que nos deu notícia de que já sabia escrever "MAÇÃ" e "PEIXE". Ele produziu 
sozinho o escrito "PXEX", após ter coberto totalmente o desenho com a caneta azul. A palavra "PEIXE", escrita no canto superior esquerdo, foi feita pelos coordenadores após a escrita de Roberto.

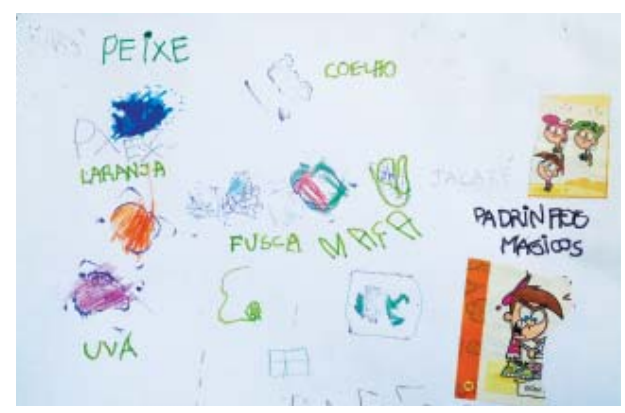

Vemos, portanto, que o desenho "cai" e surge a palavra escrita:
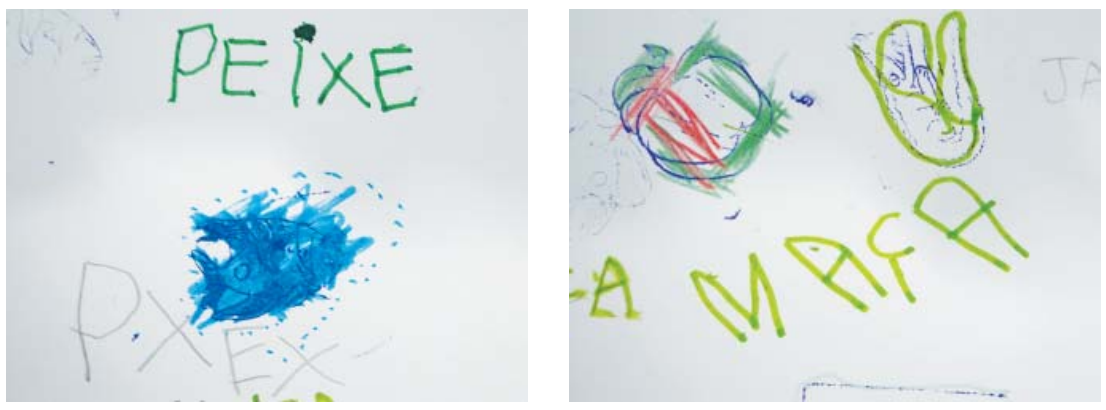

Ele passa a nos contar as rádios que costuma ouvir (NATIVA FM, TUPI FM). Cantarola com frequência, faz batuques, fala e escreve algumas frases dirigidas aos coordenadores ou colegas partilhando seus interesses (HOJE NÓS BRINCAMOS DE LEGOS/SEGUNDA, SÁBADO, DOMINGO).
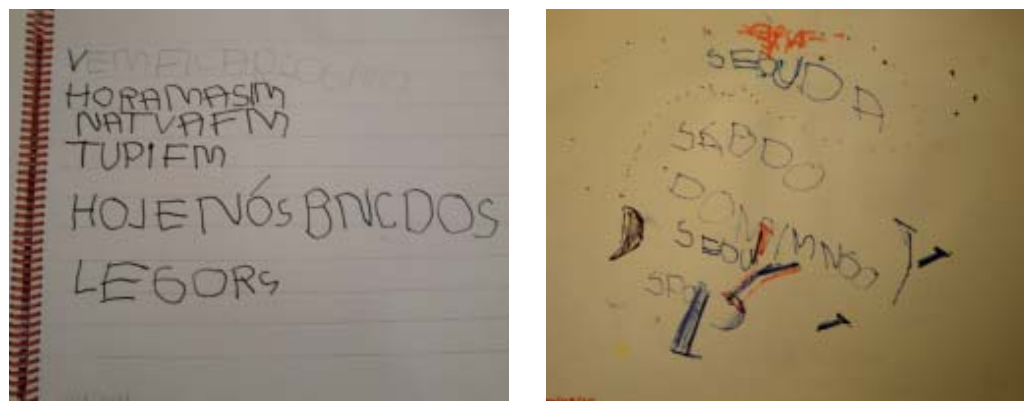

rápido avanço de Roberto no uso da escrita e suas novas possibilidades de escrever espontaneamente para partilhar seus interesses no grupo chamou a nossa 
atenção, pois não poderíamos creditar a alguns meses de trabalho terapêutico um avanço tão significativo.

No final do ano, quando mostramos as produções de Roberto para sua mãe, tivemos a resposta. Ela estava muito contente com os avanços do filho e dizia que acreditava que ele poderia aprender a ler e a escrever. Contou-nos que, quando ele estava no $1^{\circ}$ ano, tinha uma professora que acreditava muito nas capacidades dele. Apesar de Roberto não fazer as atividades que ela propunha em classe, não deixava de registrar em seu caderno todas as tarefas que passava para a turma. No final daquele ano, presenteou Roberto com o caderno e disse para sua mãe que ele estava aprendendo sim, apesar de não falar com ela nem com os colegas.
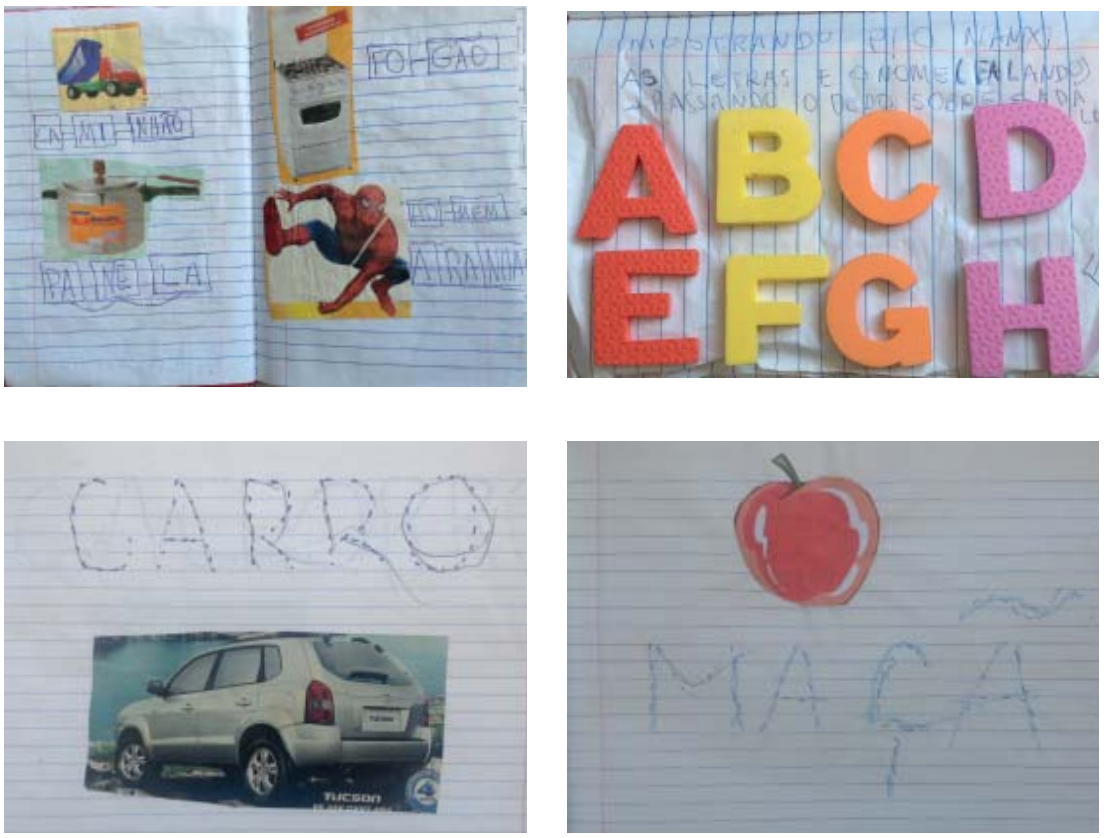

Pudemos ressignificar as produções de Roberto ao longo daquele ano no grupo e esclarecer que as "primeiras marcas" da escrita alfabética tinham sido registradas há muito tempo, graças ao dispositivo escolar criado pela professora (educar/tratando) e que o trabalho terapêutico no Grupo da Escrita (tratar/educando) pôde recuperar as marcas inscritas na proposição escolar que the foi oferecida e foram fundamentais para que Roberto pudesse construir uma escrita para falar de si e de sua relação com o mundo.

\section{CONSIDERAÇÕES FINAIS}

A história de Roberto ilustra a importância da escola como ferramenta terapêutica para as crianças com TEA, apontando a relevância de um trabalho docente não regido pela ótica desenvolvimentista das capacidades cognitivas, já que não recuou frente ao 
desafio de escolarizar um aluno que se apresentava tão aquém dos processos de alfabetização e letramento e, portanto, abriu espaço para um trabalho de educar/tratando.

Tomar a criança como aluno, apostar em suas possibilidades de educabilidade, incluindo a dimensão do sujeito psíquico, e não exclusivamente a ótica das capacidades cognitivas como organizadores do campo das aprendizagens, abre espaço para que novas formas de aprender e ensinar sejam viabilizadas no contexto escolar.

trabalho no âmbito da escrita alfabética é uma via potente e possível quando se trata da escolarização de crianças com TEA, pois possibilita a reordenação do campo simbólico com um usufruto das produções escritas para que a criança possa dizer de si e dirigir seu texto a um outro que a reconhece e a autentica.

No entanto, os resultados de tal processo nem sempre são verificáveis ao final de um ano letivo. 


\section{REFERÊNCIAS BIBLIOGRÁFICAS}

American Psychiatric Association (1995). Manual diagnóstico e estatístico de transtornos mentais (DSM-IV). Porto Alegre: Artes Médicas.

Bastos, M. B. (20I2). Incidências do educar no tratar: desafios para a clínica psicanalítica da psicose infantil e do autismo. Tese de Doutorado, Instituto de Psicologia, Universidade São Paulo, São Paulo, SP, Brasil.

Bernardino, L. M. F. (2004). As psicoses não-decididas da infância: um estudo psicanalítico. São Paulo: Casa do Psicólogo.

Chemama, R. (Org.). (1995). Dicionário de psicanálise. Porto Alegre: Artes Médicas.

Kupfer, M. C., \& Petri, R. (2000). Por que ensinar a quem não aprende? Estilos da Clínica: Revista sobre a Infância com Problemas, 5(9), 109-1 17. Recuperado de http://dx.doi. org/| 0.1 | 606/issn. 198| - |624.v5i9p 109-1 17 .

Kupfer, M. C. M. (2000). Educação para o futuro. São Paulo: Escuta.

(2007). Inconsciente e escrita: um corpo que cai. In Nascimento, E. M. V., \& Gonzales, R. C. F. (Orgs.). Psicanálise e os desafios da clínica na contemporaneidade. Salvador: EDUFBA.

(20।0). A educação terapêutica: uma nova abordagem das relações entre psicanálise e educação. In Kupfer, M. C. M., \& Noya Pinto, F. S. C. (Orgs.). Lugar de vida, vinte anos depois: exercícios de educação terapêutica. São Paulo, SP: Escuta.

Lacan, J. (1985). O seminário, livro 2: o eu na teoria de Freud e na técnica da psicanálise, 1954 1955. Rio de Janeiro: J.Z.E.

(1998). O seminário, livro 1 I: os quatro conceitos fundamentais da psicanálise, 1964. Rio de Janeiro: J.Z.E.

(2003). O seminário, livro 9: a identificação, 196 I - 1962 (I. Correa \& M. Bagno, trads.). Recife, PE: Centro de Estudos Freudianos do Recife (publicação não comercial)

Freud, S. (1976). Projeto para uma psicologia científica. In Freud, S. Edição standard brasileira das obras psicológicas completas de Sigmund Freud (trad. J. Salomão, vol. I, p.38|-517). Rio de Janeiro: Imago (trabalho original publicado em 1895).

Freud, S. (1976). Carta 52 de 6/I2/1896 a Fliess. Publicações pré-psicanalíticas e esboços inéditos. In Freud, S. Edição standard brasileira das obras psicológicas completas de Sigmund 
Concepções e proposições em Psicologia e Educação

Freud (trad. J. Salomão, vol. I, p.3 17-324). Rio de Janeiro: Imago (trabalho original publicado em 1950[1896]).

Pommier, G. (1996). Nacimiento y renacimiento de la escritura. Buenos Aires: Nueva Visión. 